\title{
Morphology of Coronary Artery Disease in a Patient with, Psoriasis Presenting with an Acute Coronary Syndrome
}

Ranjit Sharma*, Anish Hirachan, Milan Gautam

Department of cardiology, Nepal Mediciti, Lalitpur, Nepal

*Corresponding Author: Ranjit Sharma, Nepal Medi citi hospital, 44700 Bhaisepati, Lalitpur, Nepal.

Received Date: August 03, 2021; Accepted Date: September 01, 2021; Published Date: September 10,2021

Citation: Ranjit Sharma, Anish Hirachan, Milan Gautam. (2021) Morphology of Coronary Artery Disease in a Patient with, Psoriasis Presenting with an Acute Coronary Syndrome. J. Clinical Cardiology and Cardiovascular Interventions, 4(15); Doi:10.31579/2641-0419/213

Copyright: () 2021 Ranjit Sharma, This is an open-access article distributed under the terms of the Creative Commons Attribution License, which permits unrestricted use, distribution, and reproduction in any medium, provided the original author and source are credited.

\begin{abstract}
Background: This study was designed to evaluate the patterns of coronary artery disease in patients with Psoriasis presenting with acute coronary syndrome (ACS).

Methods: This was a prospective, observational study, conducted on 28 patients with Psoriasis, presenting with acute coronary syndrome undergoing coronary angiogram from September 2017 to March 2021. All patients had undergone coronary angiogram; severity and morphology of coronary lesion were analyzed. Echocardiography was used to analyze LV wall motion and LV function.

Results: The study showed that of 28 patients with Psoriasis who presented with ACS, $45.8 \%$ of patients were presented with NSTEMI, 39.2\% \% STEMI, and Unstable angina 15\%. The average time of presentation after the onset of the symptom was 14.8 hours. $66 \%$ of patients were a smoker. Coronary involvement $50 \%$ had TVD, 40\% DVD, and 10\% had SVD. In $77.6 \%$ culprit vessel was LAD, 10.4\% LCX, and 12\% RCA. In 75\% of patient's coronary lesion was located in the proximal LAD. Chronic total occlusion was found in almost $26 \%$ of patients. Extensive LV wall motion abnormality with severe LV systolic dysfunction was noted in Psoriasis patients at the time of presentation (mean LVEF=28\%).

Conclusions: Psoriasis patients presenting with ACS, associated with increased severity of coronary lesions, multivessel involvement, and depressed LV systolic function.
\end{abstract}

Keywords: coronary artery disease; acute coronary syndrome

\section{Introduction:}

An acute coronary syndrome (ACS) is the leading cause of death and disability worldwide [1]. World Health Organization data show that around 17.7 million cardiovascular disease deaths worldwide in 2015 ( $31 \%$ of all-cause mortality), of whom 7.4 million were due to coronary artery disease [2].

Psoriasis is a chronic autoimmune, relapsing inflammatory disease of the skin affecting $2 \%$ to $3 \%$, the global adult population [3]. Psoriasis can occur at any age, but the onset is usually between the ages of 18 and 35 years. A bimodal onset has been suggested with an initial peak at ages 16 to 22 years and a second peak at age 57 to 60 years [4]. The prevalence of psoriasis varies according to geographical location, with higher rates among Caucasians when compared with other ethnicities [5]. It is also argued that countries located away from the equator have shown a higher prevalence of the disease when compared to warmer climates where the reported cases are relatively lower [6]. The most common type of psoriasis, accounting for $90 \%$ of cases, is psoriasis Vulgaris, which is characterized by the presence of papulosquamous plaques of various sizes and numbers [7]. The plaque severity and degree of affected body surface area vary throughout an individual's life [8].

The life expectancy of people with psoriasis was reported to be nearly 5 years lower compared to control groups, with cardiovascular problems being the main cause of death [9]. Understanding why psoriasis is a risk factor for atherosclerosis requires a basic understanding of their shared pathogenic features. [10] A meta-analysis conducted by Choudhary et al. demonstrated that $30.3 \%$ of patients with psoriasis had metabolic syndrome [11]. A strong link between high BMI and the development of both diseases has been explained in a robust systematic review which demonstrated that the incidence and prevalence of obesity are higher in patients with psoriasis and it is independently associated with CVD [12]. Smoking is a strongly recognized risk factor for CVD [13]. It has been demonstrated that patients who smoke more than 20 cigarettes per day are associated with a twofold risk of severe psoriasis [14]. Recent studies have found a higher prevalence of metabolic syndrome $(17.8 \%, \mathrm{p}=0.021)$, CVD (4.6\%, $\mathrm{p}=0.044)$, hypertension $(32.5 \%, \mathrm{p}=0.000)$, and hyperlipidemia $(22.3 \%, \mathrm{p}=0.025)$ in patients with psoriasis, as compared with that of the controls [15]. Seventy-three (37\%) patients with psoriasis had LDL levels higher than the target LDL level proposed by the ATP III guideline [15].

Atherosclerosis is a lipid-related chronic inflammatory disease in which immune mechanisms play a pivotal role [16]. The lesions are filled with large numbers of immune cells. Similarly, Psoriasis is characterized by chronic autoimmune, relapsing inflammatory disease of the skin [17]. At the cellular level, atherosclerosis is associated with inflammatory 
cytokines, such as TNF- $\alpha$ and IL-1, which overlap with the same markers implicated in psoriasis [18].

T-helper 1 cells of the adaptive cellular immune system are integral in plaque development and inflammation propagation for both psoriasis and atherosclerosis [19]. The activated T-helper 1 cells release proinflammatory cytokines, including interferon-g, tumor necrosis factora, and interleukin-2 (20). This leads to the activation of macrophages, keratinocytes, and vascular cells, all of which release additional cytokines [21]. In addition to the role of T-helper 1 cells, proinflammatory effects of T-helper 17 cells and anti-inflammatory effects of $\mathrm{T}$ regulatory cells contribute to both pathologies. T-regulatory cells modulate the inflammatory process by secreting anti-inflammatory cytokines, such as interleukin-10 and transforming growth factor-b. Both psoriasis and atherosclerosis have reduced numbers and activity of T-regulatory cells and resultant hyperactivity of T-helper $1 / \mathrm{T}$-helper 17 cells. Therefore, psoriasis and atherosclerosis result in plaques in the skin and arteries, respectively that are a focus of both local and systemic immune activity $[22,23]$.

Chronic exposure to systemic inflammation in patients with severe psoriasis can result in coronary microvascular dysfunction (CMD). This may lead to the impairment of the coronary arteries' ability to augment coronary blood flow (vasodilator abnormality) and/or in a reduction in coronary blood flow (coronary microvascular spasm) [24]. High levels of angiotensin-converting enzyme levels, renin, and ET-1 in psoriasis are associated with an increased risk of hypertension [25]. It is believed that the adipose tissue in psoriatic patients acts as a source of angiotensinogen that is converted to angiotensin II [26].

Some of the systemic medications have side effects that increase cardiovascular risk. Cyclosporine can worsen arterial hypertension, although it infrequently causes new-onset hypertension during shortcourse, intermittent therapy [27]. Cyclosporine also can alter lipid metabolism, resulting in hyperlipidemia [28]. Systemic retinoids have been shown to increase serum triglycerides and decrease serum highdensity lipoprotein cholesterol and insulin sensitivity [29]. Methotrexate is capable of increased homocysteine levels that could tip the hemostasis balance to a prothrombotic state [30]. Cardiovascular medications may affect psoriasis. Statins, traditionally used for the treatment of hyperlipidemia and atherosclerotic disease, also have anti-inflammatory effects that could provide potential benefits in psoriasis [31]. Betablockers have been suggested to both induce and exacerbate psoriasis [32]. Selective beta-blockers, including metoprolol and atenolol, also have been reported in association with psoriasiform eruptions [33, 34]. Angiotensin-converting enzyme inhibitors have been reported to have a possible association with psoriasis. Psoriasis and psoriasiform eruptions also have been reported with angiotensin II antagonists, calcium channel blockers, and clonidine [35, 36, and 37]. Steroids have an effective role in the treatment of psoriasis but they are implicated in heart diseases. They can potentially cause hypertension by various mechanisms which include increased systemic vascular resistance, extracellular volume, and cardiac contractility. They also cause sodium retention, hypokalemia, and hypertension by altering the blood pressure regulatory system [38]

\begin{tabular}{|l|c|}
\hline Age (years) & $56.78 \pm 11.5$ \\
Sex & $(66 \%)$ \\
Male & $(34 \%)$ \\
female & $14.8 \mathrm{~h}(25 \mathrm{~min}-8$ days) \\
Duration of symptom/s & \\
& $36 \%$ \\
Risk factors & $51 \%$ \\
Diabetes Mellitus & $66 \%$ \\
Hypertension & $22 \%$ \\
Smoking & $5 \%$ \\
Dyslipidemia & \\
Family h/o of CAD & \\
& $66 \%$ \\
Presenting symptom/s: & $34 \%$ \\
Chest pain & \\
Shortness of breath & \\
Diagnosis: & $(45.8 \%)$ \\
NSTEMI & $(39.2 \%)$ \\
STEMI & $(15 \%)$ \\
Unstable Angina & $28.64 \%$ \\
Mean LV Function & \\
\hline
\end{tabular}

Table 1: Baseline characteristics of the study subjects 


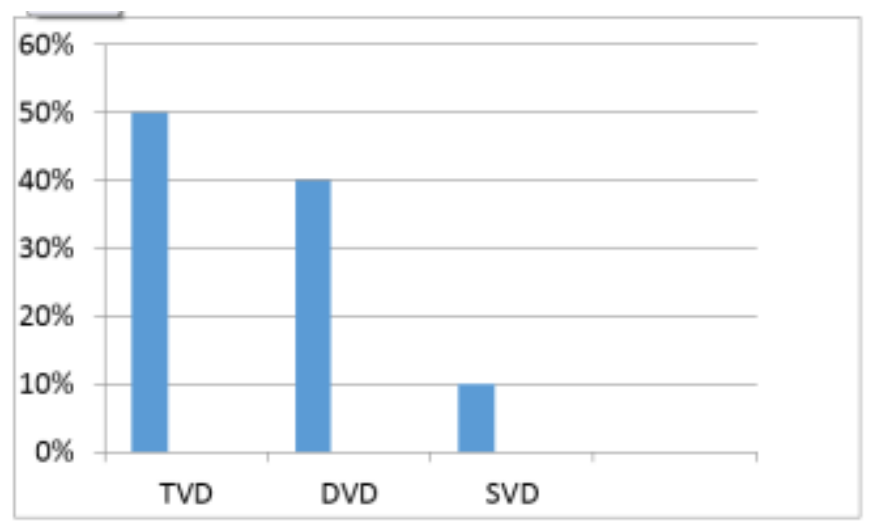

\section{Methods}

It is a retrospective, single-center study, performed at Nepal Mediciti Hospital, Nepal. A total of 28 Psoriasis patients who presented with acute coronary syndrome from September 2017 to March 2021 were enrolled in this study. In all 28 patients with Psoriasis, presenting an acute coronary syndrome left ventricular systolic function, and left ventricle wall motion analysis was done before coronary catheterization. All patients were taken to the catheterization lab for a coronary angiogram. Severity and morphology of coronary lesion were analyzed

\section{Results}

A total of 28 Psoriasis patients presenting with the acute coronary syndrome were included in the study. The average age was $56.78 \pm 11.5$ with the youngest being 26 years and the oldest being 72 years old. Most of the patients were male $66 \%$. The average time of presentation after the onset of the symptom was 14.8 hours.

The commonest symptom was chest pain $66 \%$ followed by shortness of breath in $34 \%$. The diagnosis was made base on a clinical symptom, electrocardiography findings, and cardiac biomarkers. Most of the patients $45.8 \%$ were presented with NSTMI followed by $39.2 \%$ STEMI and $15 \%$ unstable angina. Among the risk factors, smoking was the commonest and found in $66 \%$ of patients followed by hypertension $51 \%$ and diabetic $36 \%$. Coronary involvement $50 \%$ had TVD, $40 \%$ DVD, and $10 \%$ had SVD. In $77.6 \%$ culprit vessel was LAD, $10.4 \%$ LCX, and $12 \%$ RCA. In $75 \%$ of patient's coronary lesion was located in the proximal LAD. Chronic total occlusion (CTO) was found in almost $26 \%$ of patients. Extensive LV wall motion abnormality with severe LV systolic dysfunction was noted in Psoriasis patients (mean $\mathrm{LVEF}=28.64 \%$ ).

\section{Discussion}

Recent evidence has suggested that psoriasis is associated with systemic inflammation and an increased risk for developing cardiovascular disease. This has led to the concept that systemic inflammation from psoriasis may predispose to atherosclerotic initiation and progression. Recent studies have found a higher prevalence of metabolic syndrome $(17.8 \%, \mathrm{p}=0.021)$, CVD (4.6\%, p=0.044), hypertension (32.5\%, $\mathrm{p}=0.000)$, and hyperlipidemia $(22.3 \%, \mathrm{p}=0.025)$ in patients with psoriasis, as compared with that of the controls. Seventy-three (37\%) patients with psoriasis had LDL levels higher than the target LDL level proposed by the ATP III guideline. Similar findings were found in our study and showed that hypertension was found in $51 \%$, dyslipidemia in $22 \%$, and diabetes mellitus in $36 \%$.

Several studies have shown a strong association between psoriasis and angiographic coronary artery disease. Similar findings were found in our study and showed that $50 \%$ had TVD, $40 \%$ DVD, and $10 \%$ had SVD. In $77.6 \%$ culprit's vessel was LAD, $10.4 \%$ LCX, and $12 \%$ RCA. In $75 \%$ of patient's coronary lesion was located in the proximal LAD. Chronic total occlusion was found in almost $26 \%$ of patients. Extensive LV wall motion abnormality with severe LV systolic dysfunction was noted in Psoriasis patients at the time of presentation (mean $\mathrm{LVEF}=28 \%$ ).

Psoriasis has a bimodal distribution of incidence, with a first peak in patients between 20 to 30 years old and a second peak in patients 50 to 60 years of age. Because this second peak coincides with the age range that patients are also more likely to develop overt CAD. . In our study the average age was $56.78 \pm 11.5$ with the youngest being 26 years and the oldest being 72 years old.

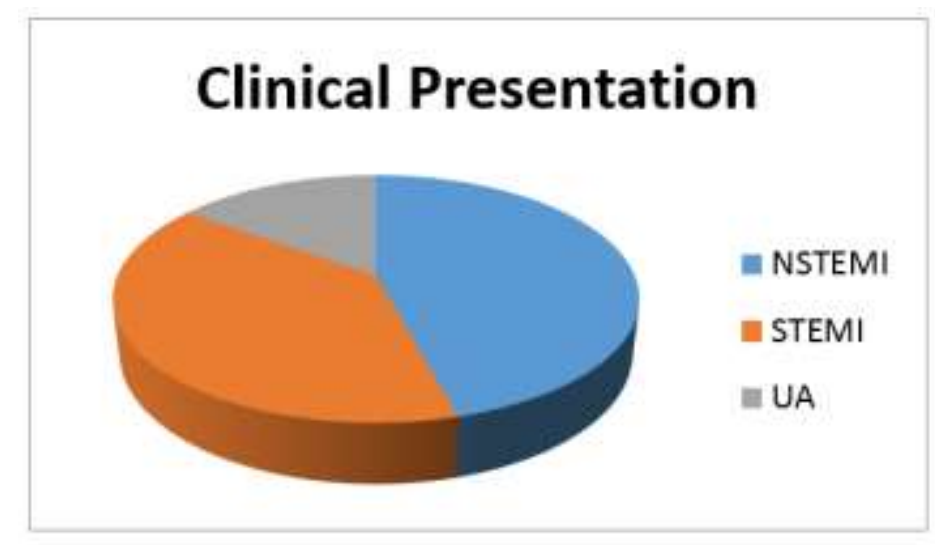




\section{Culprit Vessel for ACS}

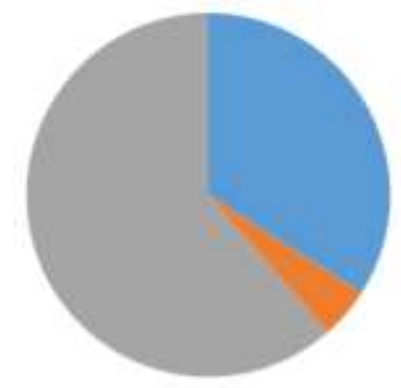

LAD

LCX

RCA

\section{Study limitations}

There are several limitations of this study. First, it is a single-center retrospective study. Second, coronary angiographic scoring was based on visual estimation at the time of cardiac catheterization. Third, IVUS and OCT were not used to interrogate the coronary lesion.

\section{Conclusion}

Psoriasis patients presenting with ACS, associated with increased severity of coronary lesions, multivessel involvement, and depressed LV systolic function. Various studies have explored the link between cardiovascular complications and psoriasis. But other avenues need to be explored and more in-depth research on a wider scale is required.

\section{References}

1. Chen W, Thomas J, Sadatsafavi M, et al. Risk of cardiovascular comorbidity in patients with chronic obstructive pulmonary disease: a systematic review and meta-analysis. Lancet Respir Med 2015; 3: 631-639.

2. World Health Organization [webpage on the Internet]. Cardiovascular Disease. 2016. [2016; cited 2016 Set]; Available from:

3. Gelfand JM, Weinstein R, Porter SB, et al. Prevalence and treatment of psoriasis in the United Kingdom: a populationbased study. Arch Dermatol. 2005; 141:1537-1541.

4. Neimann AL, Porter SB, Gelfand JM. Epidemiology of psoriasis. Expert Rev Dermatol. 2006;1:63-75

5. Langan SM, Seminara NM, Shin DB, et al. Prevalence of metabolic syndrome in patients with psoriasis: a populationbased study in the United Kingdom. J Invest Dermatol 2012; 132:556-62.

6. Parisi R, Symmons DPM, Griffiths CEM, et al. Global epidemiology of psoriasis: a systematic review of incidence and prevalence. J Invest Dermatol 2013;133:377-85.

7. Nestle FO, Kaplan DH, Barker J, et al. N Engl J Med. 2009; 361: 496-509.

8. Langley RG, Krueger GG, Griffiths CE, et al. Psoriasis: epidemiology, clinical features, and quality of life. Ann Rheum Dis. 2005;64(Suppl 2): ii 18-25

9. Abuabara K, Azfar RS, Shin DB, et al. Cause-specific mortality in patients with severe psoriasis: a population-based cohort study in the UK. Br J Dermatol 2010; 163:586- 92.

10. Neimann AL, Shin DB, Wang X, et al. Prevalence of cardiovascular risk factors in patients with psoriasis. J Am Acad Dermatol. 2006; 55: 829-835.
11. Choudhary S, Pradhan D, Pandey A, et al. The association of metabolic syndrome and psoriasis: A systematic review and meta-analysis of observational study. Endocr Metab Immune Disord Drug Targets 2020; 20:703-17.

12. Sterry W, Strober BE, Menter A, et al. Obesity in psoriasis: the metabolic, clinical and therapeutic implications. Report of an interdisciplinary conference and review. Br J Dermatol 2007; 157:649-55.

13. Gerdes S, Zahl VA, Weichenthal M, et al. Smoking and alcohol intake in severely affected patients with psoriasis in Germany. Dermatology 2010;220:38-43

14. Fortes C, Mastroeni S, Leffondré K, et al. Relationship between smoking and the clinical severity of psoriasis. Arch Dermatol 2005; 141:1580-4.

15. Choi WJ, Park EJ, Kwon IH, Kim KH, et al: Association between psoriasis and cardiovascular risk factors in Korean patients. Ann Dermatol. 2010, 22:300-306.

16. S ranjit, Li da chu et al. Potential role of dendritic cells for progression of atherosclerotic lesions. Postgrad Med J 2006; 82:573-575.

17. Ann G. Coumbe, MD, Marc R. Pritzker, MD, et al.Cardiovascular Risk, and Psoriasis: Beyond the Traditional Risk Factors. The American Journal of Medicine (2014) 127, 12-18

18. Hahn BH, Grossman J, Chen W, McMahon M, et al. The pathogenesis of atherosclerosis in autoimmune rheumatic diseases: roles of inflammation and dyslipidemia. J Autoimmun 2007;28:69-75

19. Szabo SJ, Sullivan BM, Peng SL, et al. Molecular mechanisms regulating Th1 immune response. Annu Rev Immunol. 2003; 21:713-758.

20. Cai Y, Fleming C, Yan J. New insights of T cells in the pathogenesis of psoriasis. Cell Mol Immunol. 2012; 9:302-309.

21. Elloso MM, Gomez-Angelats M, Fourie AM, et al. Targeting the Th17 pathway in psoriasis. J Leukoc Biol. 2012;92:11871197

22. Cheng X, Yu X, Ding YJ, et al. The Th17/Treg imbalance in patients with the acute coronary syndrome. Clin Immunol. 2008;127:89-97

23. De Boer OJ, van der Meer JJ, Teeling P, et al. Low numbers of FOXP3 positive regulatory $\mathrm{T}$ cells are present in all developmental stages of human atherosclerotic lesions. PLoS ONE. 2007; 2:e779.

24. Piaserico S, Osto E, Famoso G, et al. Long-term prognostic value of coronary flow reserve in psoriasis patients. Atherosclerosis 2019; 289:57-63. 
25. Armstrong AW, Lin SW, Chambers CJ, et al. Psoriasis and hypertension severity: results from a case-control study. PLoS One 2011; 6:e18227.

26. Salihbegovic EM, Hadzigrahic N, Suljagic E, et al. Psoriasis and high blood pressure. Med Arch 2015; 69:13-5.

27. Wakkee M, Thio HB, Prens EP, et al. Unfavorable cardiovascular risk profiles in untreated and treated psoriasis patients. Atherosclerosis. 2007;190:1-9

28. Hoorn EJ, Walsh SB, McCormick JA, et al. Pathogenesis of calcineurin inhibitor-induced hypertension. J Nephrol 2012; 25:269-75.

29. Corbetta S, Angioni R, Cattaneo A, et al. Effects of retinoid therapy on insulin sensitivity, lipid profile and circulating adipocytokines. Eur J Endocrinol. 2006;154:83-86

30. Prodanovich S, Ma F, Taylor JR, et al. Methotrexate reduces the incidence of vascular diseases in veterans with psoriasis or rheumatoid arthritis. J Am Acad Dermatol. 2005;52:262-267

31. Brauchli YB, Jick SS, Meier CR, et al. Statin use and risk of first-time psoriasis diagnosis. J Am Acad Dermatol. 2011; 65:77-83.
32. Abel EA, DiCicco LM, Orenberg EK, et al. Drugs in exacerbation of psoriasis. J Am Acad Dermatol. 1986; 15:10071022.

33. White WB, Schulman P, McCabe EJ, et al. Psoriasiform reaction to atenolol. Arch Dermatol. 1986; 122:857-858.

34. Neumann HA, van Joost T. Adverse reactions of the skin to metoprolol and other beta-adrenoreceptor blocking agents. Dermatologica. 1981;162: 330-335

35. Marquart-Elbaz C, Grosshans E, Alt M, Lipsker D. Sartans, angiotensin II receptor antagonists, can induce psoriasis. Br J Dermatol. 2002;147:617-618

36. Cohen AD, Kagen M, Fridge M, Halevy S. Calcium channel blockers intake and psoriasis: a case-control study. Acta Derm Venereol. 2001;81:347-349

37. Wilkin J. Exacerbation of psoriasis during clonidine therapy. Arch Dermatol. 1981;117:4

38. Foy MC, Vaishnav J, Sperati CJ. Drug-induced hypertension. Endocrinol Metab Clin North Am 2019;48:859-73

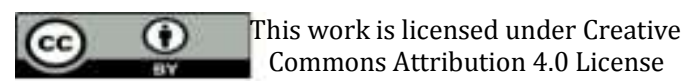

To Submit Your Article Click Here: Submit Manuscript

DOI: $10.31579 / 2641-0419 / 213$

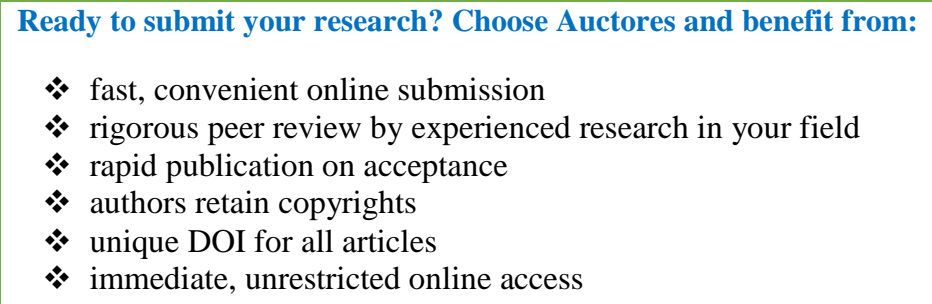

At Auctores, research is always in progress.

Learn more www.auctoresonline.org/journals/clinical-cardiology-andcardiovascular-interventions 